Thorax (1972), 27, 239.

\title{
Aortic arch aneurysm
}

\section{Resection and replacement: protection of the nervous system ${ }^{1}$}

\author{
ROWAN NICKS \\ Cardio-thoracic Surgical Unit, Royal Prince Alfred Hospital, Sydney, Australia
}

\begin{abstract}
A patient with an aortic arch aneurysm, who was submitted to resection and replacement by a prosthetic graft during a 36-minute period of cerebral arterial occlusion at $20^{\circ} \mathrm{C}$, and who subsequently died of ischaemic brain damage, is reported.

Current methods for protection of the central nervous system from ischaemic damage during operations of this type are reviewed. It is considered that total body perfusion, including all arteries which supply the circle of Willis, with hypothermia as low as $20^{\circ} \mathrm{C}$, will provide the safest background to a successful operation.
\end{abstract}

Hypothermia of varying degrees has been used successfully to protect the brain and other vital organs from anoxic brain damage during periods of induced circulatory arrest.

This state is sometimes a necessary background to special surgical operations on the heart and great vessels (Gollan, Phillips, Grace, and Jones, 1955 ; Drew and Anderson, 1959; Kirklin and Devloo, 1961 ; Dubost, Blondeau and Piwnica, 1962 ; Belsey, Dowlatshahi, Keen, and Skinner, 1968 ; Lillehei, Todd, Levy, and Ellis, 1969).

The unexpected occurrence of severe brain damage in an elderly patient after undergoing a prosthetic replacement of the aortic arch for an aneurysm has prompted a review of the problem of its protection in this situation and a search for a safe method of management.

\section{CASE HISTORY}

G.C., a 68-year-old woman, Royal Prince Alfred Hospital Unit No. 300333, was admitted to the Page Chest Pavilion on 24 June 1970 complaining of a dull retrosternal chest pain which radiated to the back between the shoulders, to the neck under the mandibles, and down the left arm. The pain was aggravated by minor exertion and was relieved by rest.

PAST HISTORY This patient had been under treatment for 10 years for hypertension, which, at the time of admission, was controlled by reserpine. In 1965 , at a time when she was confined to bed with an exacerbation of hypertension, she developed a sudden severe retrosternal pain when getting out of bed and collapsed. She was diagnosed as myocardial infarction.

1Delivered to the Scientific Meeting, Royal Australian College of Surgeons, 3 May 1971.
ON EXAMINATION Blood pressure was $160 / 100 \mathrm{mmHg}$, pulse rate $76 / \mathrm{min}$, sinus rhythm. The heart sounds were normal and no murmurs were detected in the precordium or along the carotid arteries. The peripheral pulses were equal. The electrocardiogram showed evidence of hypertrophy of the left ventricle with ST-T wave changes.

The chest radiograph showed a localized calcified aneurysm of the aortic arch (Fig. 1a) shown on an arch aortogram (Bernstein) to extend across the midline to include a brachiocephalic trunk, from which arose the innominate and left common carotid arteries (Fig. 1b). The coronary arteries were patent.

At oesophagoscopy the oesophageal lumen was seen to be compressed at the level of the aortic arch.

OPERATION On 14 July 1970 excision of the aneurysm and restoration of the aortic continuity was undertaken. The external iliac artery was first isolated for later perfusion and the lesion was exposed by means of a median sternotomy incision (Fig. 2). The leash of brachiocephalic arteries, the separate left subclavian artery, and the descending aorta beyond this were dissected and taped. Cardiopulmonary bypass (right atrium to iliac artery) was instituted $\left(2 \cdot 2\right.$ litres $\left./ \mathrm{m}^{2}\right)$, the left ventricle was vented, and the temperature was slowly lowered over a 20-minute period to $20^{\circ} \mathrm{C}$, measured in the nasopharynx, the temperature gradient between the arterial and venous blood being maintained below $10^{\circ} \mathrm{C}$.

When the temperature was stable, the aortic arch was clamped obliquely so that the origins of all the brachiocephalic branches were included in an upper ellipse (Fig. 3), the aorta was incised at its proximal origin, and coronary perfusion was instituted. The right coronary artery could not be cannulated because of atheromatous deposits at its origin, but an 


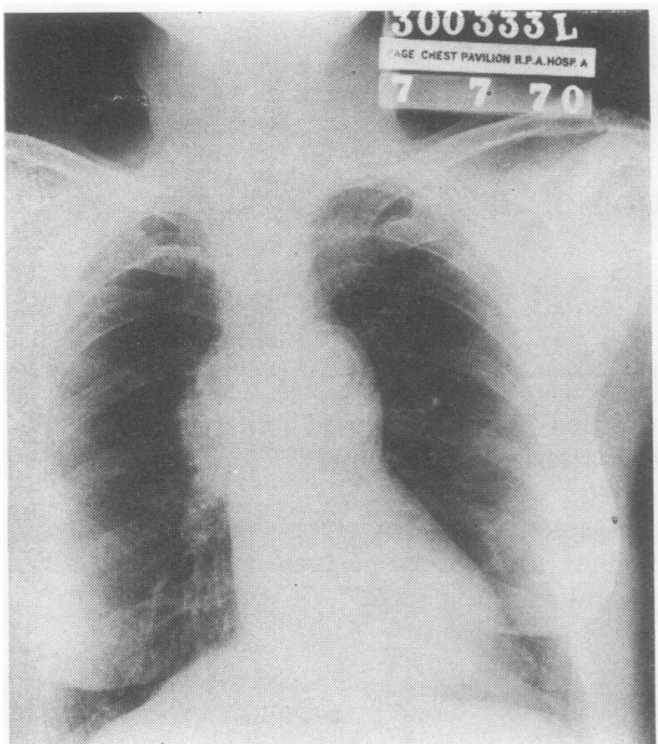

a

(b) arch aortogram showing involvement of the aortic arch.

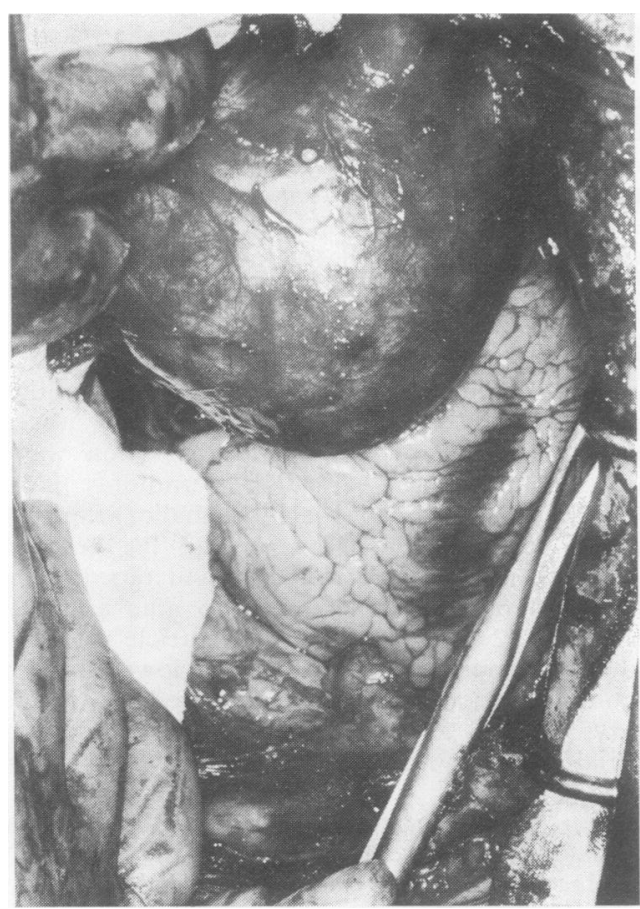

FIG. 2. Sternotomy exposure of the aneurysm, showing its relation to the heart and the aortic arch. The brachiocephalic vessels have been taped. adequate flow through the left coronary artery was considered to be adequate at the low temperature.

The thin-walled clotted saccular aneurysm was? excised, leaving healthy cuffs for suture. A $30 \mathrm{~mm}^{3}$ diameter woven Dacron graft, $4 \mathrm{~cm}$ in length and cut obliquely at its upper end to fit the ellipse? proximal to the origin of the great arteries, was in serted. When this upper suture line had been com 0 pleted and the graft filled with saline, the aortic clamp was gently released and replaced proximal too the origin of the brachiocephalic lease (which laye deeply and above the graft), thus restoring normak perfusion to the brain (Fig. 3). Great care was taken to avoid the occurrence of air embolism.

The period of total occlusion of the cerebral cir- -5 culation was 36 minutes, and this was considered safe $P$

As soon as the lower end of the graft had been. sutured to the ascending aorta, all clamps were re+N moved and the patient was rewarmed. The total times taken for removal and restoration had been 680 minutes.

A temporary isoprenaline-adrenaline infusion was necessary to maintain her blood pressure in the operating theatre, and a tracheostomy was performed On her return to the intensive care ward, the heare was in sinus rhythm, pulse rate $100 / \mathrm{min}$, B.P. $240 \%$ $130 \mathrm{mmHg}$, C.V.P. $20 \mathrm{mmHg}$. Her chest was clear̃ and her general condition good; but it became obvious that she had sustained anoxic brain damage for she remained unconscious and only responded to supra-orbital painful stimulation. Her pupils were dilated and fixed. Examination of the fundi revealeck normal discs and no haemorrhage. 


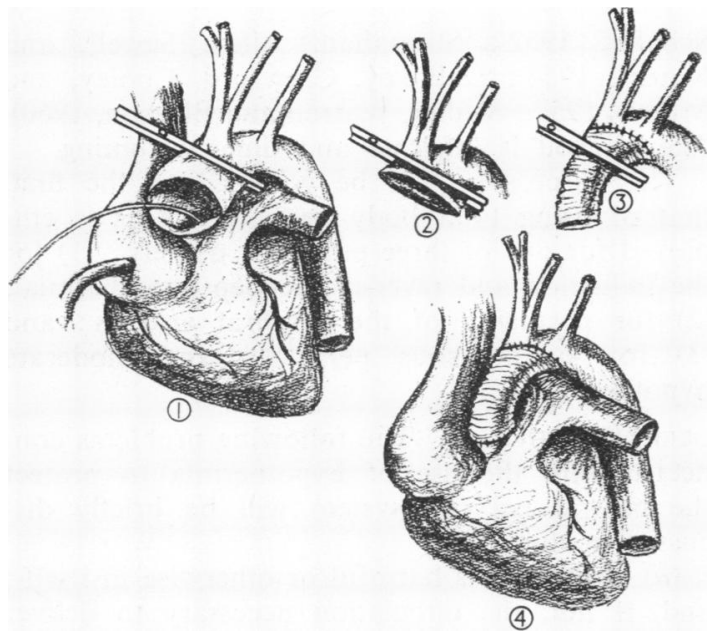

FIG. 3. Excision and replacement of the aneurysm: (1) atrio-iliac bypass with left coronary artery perfusion. The aorta has been clamped obliquely; (2) excision of aneurysm; (3) reclamping after suture of the upper end in order to restore cerebral circulation-occlusion time 36 minutes; (4) final restoration.
On the following day she remained comatose. The pupils were small, her reflexes exaggerated, and the signs were those of generalized damage to the brain.

Her condition deteriorated progressively, her blood pressure fell, and she died 36 hours after operation.

CORONER'S NECROPSY The relevant findings were as follows :

The whole brain and brain stem was soft, and there were no local areas of haemorrhage or particular involvement.

The carotid arteries were patent and relatively free from atheroma. There was a moderate degree of atheroma in the vessels at the base of the brain, but all were patent.

The heart weighed $350 \mathrm{~g}$. The coronary arteries were grossly atheromatous and the myocardium was patchily fibrotic. The heart valves were normal. Two centimetres above the aortic valve, a prosthetic graft, $4 \mathrm{~cm}$ in length, had been inserted. The anastomoses were intact. The aorta adjacent to the sutures was moderately atheromatous.

The lungs were mildly congested and oedematous, and pleural cavities contained $300 \mathrm{ml}$ of clear transudate.

The liver was moderately congested and the kidneys and adrenal glands were normal.

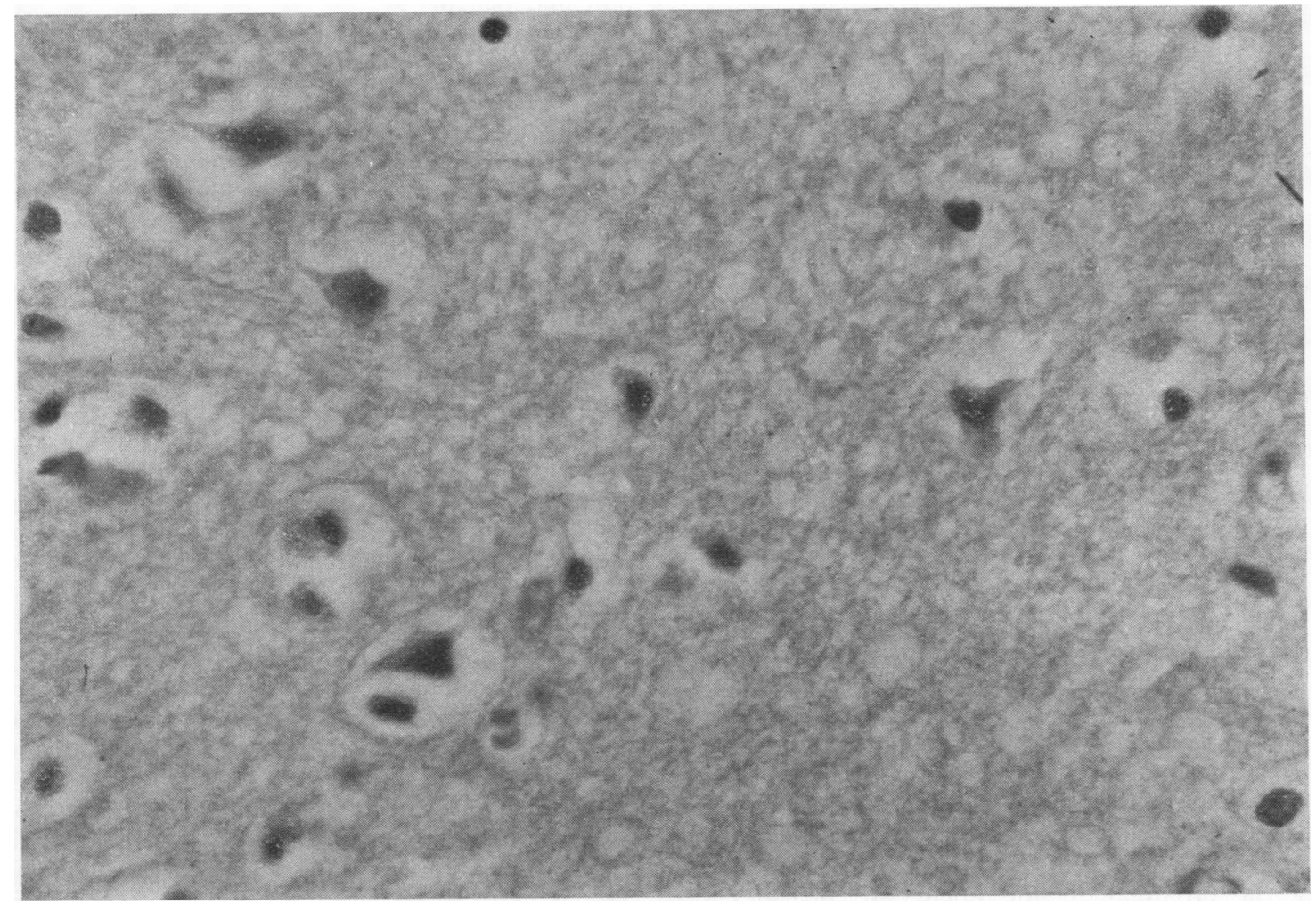

FIG. 4. Microscopic section of the brain, showing diffuse necrosis of the neurones of the grey matter. H. \& E. $\times 510$. 
MICROSCOPY Examination of the brain showed an extensive diffuse necrosis (Fig. 4) of the neurones throughout the grey matter of the brain.

Examination of the heart showed a patchy fibrosis of the myocardium together with severe atheroma of the coronary arteries.

\section{COMMENTS}

1. Hypothermia at $20^{\circ} \mathrm{C}$ failed to protect the central nervous system of this patient during a 36-minute period of occlusion of both brachiocephalic vessels. According to the current literature on this subject, severe brain damage should not have occurred. The hypothermic state was supervised by an experienced operator and induced slowly by means of a heat exchanger included within the total extracorporeal body perfusion circuit. The circulation, $2 \cdot 2$ litres $/ \mathrm{m}^{2}$, was delivered by right atrial to iliac artery bypass, and the temperature in the heat exchanger was controlled so that the gradient between the arterial and venous blood was always less than $10^{\circ} \mathrm{C}$. The nasopharyngeal temperature was well stabilized at $20^{\circ} \mathrm{C}$, and the operator was satisfied that there was no discrepancy between this and the brain mass.

2. There were no significant technical problems. The oblique section of the aorta allowed its reconstruction by a single suture line which placed the prosthesis proximal and anterior to the origin of the brachiocephalic vessels. There was no air embolism. Free oozing was controlled in the operating theatre by local means and by the transfusion of fresh blood when bypass had been discontinued and the heparin neutralized.

The complete failure of hypothermia at $20^{\circ} \mathrm{C}$ to protect the central nervous system, as demonstrated in the widespread infarction of its grey matter, was disappointing and emphasized a need for supplementary methods.

\section{D:SCUSSION}

If this operation is to be more than an occasional dangerous tilt, the basic challenge - that of maintaining the brain in a healthy state during the procedure - must be met and vanquished.

Two methods for safeguarding the central nervous system have been developed-one in which total body perfusion is used, and the other using a bypass shunt, which, after its placement in the aorta proximal to the aneurysm, provides the means for perfusing the brain by the heart itself at a normal temperature (Hardin, Batchelder, and
Schafer, 1952 ; Stranahan, Alley, Sewell, and을 Kausel, 1955; DeBakey, Crawford, Cooley, and드 Morris, 1957 ; Muller, Warren and Blanton, 1960) $\frac{\bar{\rho}}{\bar{D}}$ The method is intricate and time-consuming.

This discussion will be confined to the first that of using total body perfusion. This is em= ployed for one of three purposes, namely: (1) for

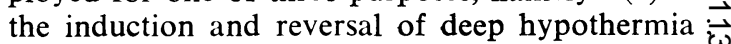
(2) for perfusion of the cerebral arteries; and (3) for simultaneous perfusion and moderate्ट्र hypothermia.

DEEP HYPOTHERMIA The following problems conit nected with the use of hypothermia to protectu the central nervous system will be briefly dis 0 cussed, namely:

(a) whether it is harmful or otherwise in itself and, if not, the circulation necessary to delive adequate oxygen and to maintain the nervoush tissues without harm at low temperatures;

(b) whether it gives protection to the brain cells when the circulation has been arrested, and for what safe period;

(c) whether the lungs are damaged by congess tion and oedema;

(d) whether there is a bleeding problem, and if so, what is its mechanism and how can this be rectified.

(a) The temporary induction of hypothermi as low as $25^{\circ} \mathrm{C}$ and its subsequent elevation bye means of a heat-exchanger and a disc oxygenatop. using the cardiopulmonary bypass techniques routinely employed in experienced clinics is re응 latively harmless in itself and gives protection to the myocardium against hypoxic damage, whict would otherwise occur when the aortic root is clamped in order to provide a relaxed and bloodê free field for the repair of some congenital hear色 malformations, and this does not harm the braing

Experimentally, hypothermia at $15^{\circ} \mathrm{C}$ gives complete protection to the central nervous systen of dogs, when the circulation is arrested for $3 \overline{\mathrm{Q}}$ minutes (White and Donald, 1962).

At this temperature there is a steady uptake of oxygen, for example, $23 \%$ of normothermic value at $20^{\circ} \mathrm{C}$ and $17 \%$ at $15^{\circ} \mathrm{C}$ (Cheng et al., 1959옹 Kameya, Oz, Neville, and Clowes, 1960). This upo take is increased if the high flow principle is use (Clowes, Neville, Sabga, and Shibota, 1958) an\& haemodilution employed.

Animals in which the circulation is arrested fo $\bar{\Phi}$ more than 60 minutes following rapid cooling t 8 $10^{\circ} \mathrm{C}$ show severe brain damage at necrops $\frac{\vec{D}}{8}$ This is more severe when a bubble oxygenator is used (Trede, Foote and Maloney, 1961). If the cooling is induced rapidly, the damage resulting 
from arrest for 30 to 60 minutes is more marked than if it is done slowly. This is attributed to residual temperature gradients remaining between the brain mass and its vascular system (Edmunds, Folkman, Snodgress and Brown, 1963 ; Connolly, Roy, Guernsey, and Stemmer, 1965). As the brain vessels are congested in the hypothermic state, it would not appear necessary to change the $\mathrm{PCO}_{2}$ of the respiratory gas to do this, as advised by Belsey et al. (1968), except to keep this within normal limits.

In the clinical field, the exact application of this experimental knowledge and the place of hypothermia is still debated (Connolly et al., 1965 ; Neville, 1968 ; Belsey et al., 1968).

In summary, it is clear that a degree of protection may be safely given to the nervous system by the induction of hypothermia to $15^{\circ} \mathrm{C}$ using modern cardiopulmonary bypass techniques, and that the major drawbacks are a time limit to the operation and postoperative oozing.

Intermittent arrest of the circulation at temperatures between $15^{\circ} \mathrm{C}$ and $20^{\circ} \mathrm{C}$ for 8-minute periods, allowing 5-minute intervals for recovery, has been safely developed in neurosurgery as an aid to the exposure and clipping of cerebral aneurysms (Gonski et al., 1964 ; Connolly et al., 1965). This technique, which proved time-consuming and predisposed to postoperative oozing, has now been supplanted in our unit by intermittent temporary occlusion, under mild surfaceinduced hypothermia, of the origins of the brachiocephalic branches from the aorta which are exposed simultaneously with the neurosurgical operation in progress by means of an upper sternotomy incision by the thoracic surgeon working independently of the neurosurgeon (Gye et al., 1969).

Temporary circulatory arrest at $15^{\circ} \mathrm{C}$ has been widely practised for short cardiac operations requiring accurate suture, namely for closure of an aortopulmonary window or a Potts anastomosis, and for arrest of bleeding occurring during dissection of a previous Blalock shunt performed as a preliminary to total repair of tetralogy of Fallot. This is without sequelae, provided precautions are taken against embolism, and provided the occlusion time does not exceed 30 minutes (Kirklin and Devloo, 1961 ; Lillehei et al., 1969). This has been our experience also in the limited number of cases in which it has been used.

If circulatory arrest is prolonged beyond this period, brain damage - the amount progressively increasing in severity with the time of occlusion, the age of the patient, and the subsequent impairment of the circulation-is feared by most surgeons, even after protection by low temperatures.

However, unpredictable brain damage has occurred in patients with circulatory arrest for 30 to 60 minutes. While some (Björk and Hultquist, 1960 ; Johnston, Ushiro, Finley, and Gerbode, 1966) deaths in this series may have been due to rapid cooling and arrest of the circulation before
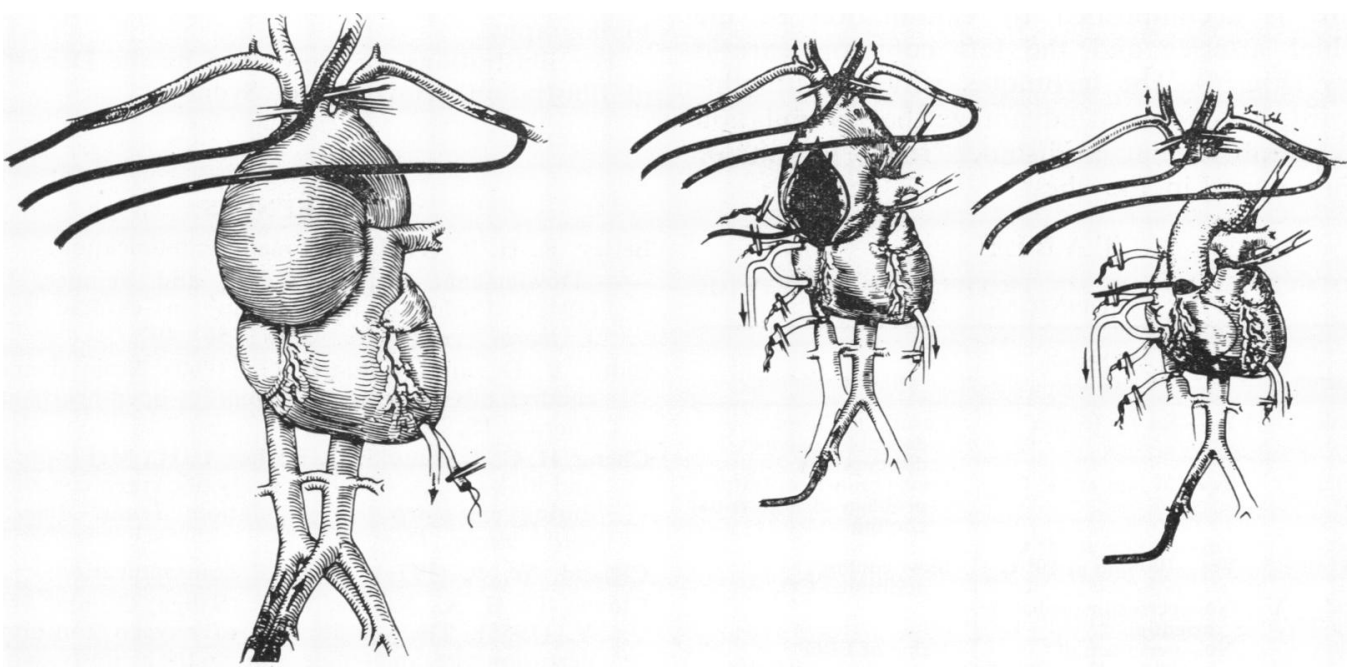

FIG. 5. Diagram of resection of an aortic aneurysm involving the aortic arch with perfusion of all arteries of the circle of Willis (M. E. DeBakey, 1971). 
equilibrium between the vessels and the brain mass had been attained, these reports are nevertheless disturbing. The incidence of this complication was much less in other series in which slow cooling was employed (Drew and Anderson, 1959 ; Dubost et al., 1962 ; Belsey et al., 1968).

(b) At temperatures as low as $15^{\circ} \mathrm{C}$, no damage to the lungs has been observed within a period of temporary circulatory arrest.

(c) No abnormality of the clotting mechanism has been observed, except in the presence of cold agglutinins. If these agglutinins are present, it is our opinion that the induction of hypothermia is best avoided.

(d) Postoperative oozing after prolonged deep hypothermia is often a problem, and is due to relaxation of the peripheral vessels and to a temporary depletion of platelets. Fresh blood is always made available for transfusion in case of need.

\section{BRAIN PERFUSION BY CARDIOPULMONARY BYPASS}

As the time limit is likely to be exceeded in an operation of the magnitude of resection and replacement of an aortic arch aneurysm (Crawford, Fenstermacher, Richardson, and Sandiford, 1970), it would seem necessary to maintain a circulation to the brain during the procedure.

Recently, a method has been elaborated for perfusing all vessels feeding the circle of Willis, as well as the rest of the body, during total cardiopulmonary bypass (Pearce, Weichert, and del Real, 1969).

This is accomplished by cannulation of the brachial arteries and the left common carotid artery (Fig. 5). The technique, which is straightforward, has the great advantage that cannulation is accomplished at a distance from the major operation site in the chest.

T A B L E

HYPOTHERMIA FOR BRAIN PROTECTION: SURVEY OF OPINIONS

\begin{tabular}{|c|c|c|}
\hline Surgeon & $\begin{array}{l}\text { Is Hypothermia } \\
\text { Adequate? }\end{array}$ & Other Comment \\
\hline Gerbode & Yes-for $10-15 \mathrm{~min}$ & $\begin{array}{l}\text { Carotid perfusion } \\
\text { desirable; results } \\
\text { discouraging }\end{array}$ \\
\hline Maloney & Yes- $-24 \mathrm{~min}$ at $20^{\circ} \mathrm{C}$ & $\begin{array}{l}\text { Direct brain temperature; } \\
\text { problem of differential } \\
\text { cooling }\end{array}$ \\
\hline $\begin{array}{l}\text { Wooler } \\
\text { Belsey }\end{array}$ & $\begin{array}{l}\text { Yes-35 min at } 15^{\circ} \mathrm{C} \\
\text { Yes-100 min at } 10^{\circ} \mathrm{C}\end{array}$ & Slow cooling; \\
\hline Cleland & $\begin{array}{l}\text { No-perfusion probably } \\
\text { essential }\end{array}$ & \\
\hline DeBakey & $\begin{array}{l}\text { No-perfusion of } \\
\text { carotid and vertebro- } \\
\text { basilar systems needed }\end{array}$ & $\begin{array}{l}\text { Value of EEG } \\
\text { monitoring stressed }\end{array}$ \\
\hline
\end{tabular}

SiMULTANEOUS CEREBRAL PERFUSION AND A $\overrightarrow{0}$ MODERATE DEGREE OF HYPOTHERMIA This, in $\frac{C}{0}$ theory, would provide additional protection to the brain from minor deficiency of circulation occur- $\overline{\mathrm{D}}$ ring under bypass conditions, without adding to
the risk of postoperative oozing.

In an endeavour to find a practical answer to $\overrightarrow{0}$ this complex problem, six cardiothoracic surgeons $\overrightarrow{-}$ of wide experience in America and Great Britain were asked for their views. Their replies (summarized in the Table) indicate a diversity of $\vec{x}$ opinion and suggest that further exact clinical $N$ experience needs to be gathered in order to clarify the animal experimental research work.

\section{TECHNICAL CONSIDERATIONS}

1. The origins of the brachiocephalic vessels may be retained in the healthy aortic segment or re-今 attached to the aortic prosthesis en bloc (Pearce $\overrightarrow{0}$ et al., 1969).

2. Air embolism is a hazard which is guarded against by removing the clamps placed on the origins of the brachiocephalic vessels only when the aortic circulation has been restored and allo air removed from the graft.

The advice received from Drs. R. Belsey, M.⿳亠二口犬 DeBakey, W. P. Cleland, Frank Gerbode, J. Maloney, M. Paneth, and G. Wooler is gratefully acknowledged.

Dr. DeBakey kindly supplied me with Fig. 5 and I would like to thank him for his encouragemento and assistance.

Miss Brenda Heagney gave valuable help with the bibliography.

The illustrations were provided by the Department of Illustration, University of Sydney.

\section{REFERENCES}

Belsey, R. H. R. (1971). Personal communication.

- Dowlatshahi, K., Keen, G., and Skinner, D. B. (1968). Profound hypothermia in cardiac surgery. J. thorac. cardiovasc. Surg., 56, 497.

Björk, V. O., and Hultquist, G. (1960). Brain damage incw children after deep hypothermia for open-heart surgery Thorax, 15, 284.

Cheng, H. C., Kusunoki. T., Bosher, L. H., McElvein, R. B. and Blake, D. A. (1959). A study of oxygen consumptions during extracorporeal circulation. Trans. Amer. Soc: artif. intern. Org., 4, 273.

Cleland, W. P. (1971). Personal communication.

Clowes, G. H. A., Neville, W. E., Sabga, G., and Shibota Y. (1958). The relationship of oxygen consumption perfusion rate, and temperature to the acidosis associate with cardiopulmonary circulatory bypass. Surgerik 44, 220. 
Connolly, J. E., Roy, A., Guernsey, J. M., and Stemmer, E. A. (1965). Bloodless surgery by means of profound hypothermia and circulatory arrest. Ann. Surg., 162, 724.

Crawford, E. S., Fenstermacher, J. M., Richardson, W., and Sandiford, F. (1970). Reappraisal of adjuncts to avoid ischemia in the treatment of thoracic aortic aneurysms. Surgery, 67, 182.

DeBakey, M. E. (1971). Personal communication.

, Crawford, E. S., Cooley, D. A., and Morris, G. C. (1957). Successful resection of fusiform aneurysm of aortic arch with replacement by homograft. Surg. Gynec. Obstet., 105, 657.

Drew, C. E., and Anderson, I. M. (1959). Profound hypothermia in cardiac surgery: report of three cases. Lancet, $1,748$.

Dubost, C., Blondeau, P., and Piwnica, A. (1962). Symposium on deep hypothermia in cardiac surgery. Extracorporeal circulation during profound hypothermia with prolonged total circulatory arrest. J. cardiovasc. Surg. (Torino), 3, 286.

Edmunds, L. H., Folkman, J., Snodgress, A. B., and Brown, R. B. (1963). Prevention of brain damage during profound hypothermia and circulatory arrest. Ann. Surg., $157,637$.

Gerbode, F. L. A. (1971). Personal communication.

Gollan, F., Phillips, R., Grace, J. T., and Jones, R. M. (1955). Open left heart surgery in dogs during hypothermic asystole with and without extracorporeal circulation. J. thorac. Surg., 30, 626.

Gonski, A., Johnston, J. B., Hercus, V. M., Rollison, R. A., and Nield, J. (1964). Profound hypothermia for intracranial surgery: case report. Med. J. Aust., 1, 318.

Gye, R., Segelov, J., Nicks, R., Cartmill, T., Bookallil, M., and Clarke, B. (1969). Control of the cerebral circulation in the surgical treatment of ruptured intracranial aneurysms. Med. J. Aust., 1, 263.
Hardin, C. A., Batchelder, T. L., and Schafer, P. W. (1952). Temporary use of polyethylene shunts in the resection and homologous graft replacement of the aortic arch in the dog. Surgery, 32, 219.

Johnston, J. B., Ushiro, C., Finley, K. H., and Gerbode, F. (1966). Profound hypothermia with prolonged circulatory arrest: an experimental study. Thorax, 21, 391.

Kameya, S., Oz, M., Neville, W. E., and Clowes, G. H. A. (1960). A study of oxygen consumption during profound hypothermia induced by perfusion of the entire body. Surg. Forum, 11, 190.

Kirklin, J. W., and Devloo, R. A. (1961). Hypothermic perfusion and circulatory arrest for surgical correction of tetralogy of Fallot with previously constructed Potts' anastomosis. Dis Chest, 39, 87.

Lillehei, C. W., Todd, D. B., Levy, M. J., and Ellis, R. J. (1969). Partial cardiopulmonary bypass, hypothermia, and total circulatory arrest: a lifesaving technique for ruptured mycotic aortic aneurysms, ruptured left ventricle, and other complicated cardiac pathology. J. thorac. cardiovasc. Surg., 58, 530.

Muller, W. H., Warren, W. D., and Blanton, F. S. (1960). A method for resection of aortic arch aneurysms. Ann. Surg., 151, 225.

Neville, W. E. (1968). Discussion of paper by Belsey et al. J. thorac. cardiovasc. Surg., 56, 516.

Paneth, M. (1971). Personal communication.

Pearce, C. W., Weichert, R. F., and del Real, R. E. (1969). Aneurysms of the aortic arch: simplified technique for excision and prosthetic replacement. J. thorac. cardiovasc. Surg., 58, 886.

Stranahan, A., Alley, R. D., Sewell, W. H., and Kausel, H. W. (1955). Aortic arch resection and grafting for aneurysm employing an external shunt. J. thorac. Surg., 29, 54.

Trede, M., Foote, A. V., and Maloney, J. V. (1961). Pathophysiologic aspects of profound hypothermia with extracorporeal circulation. Ann. Surg., 154, 210.

White, R. J., and Donald, D. E. (1962). Selective hypothermic perfusion and circulatory arrest. Arch. Surg., 84, 292.

Wooler, G. (1971). Personal communication. 